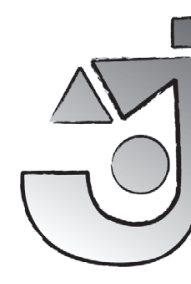

\title{
From Toddlers to Teens: The Colonization of Childhood the Disney Way
}

-Natalie Coulter

As I read both Kristine Moruzi's and Kristine

Alexander's articles on girlhood, I am struck by some of the similarities that underlie their work and mine. It seems to me that our understanding of children and youth is grounded in the same theoretical logic, particularly a poststructuralist approach that appreciates the power of discourse to produce rather than reflect reality. Poststructuralist epistemologies recognize that categories of being such as girlhood are socially constructed by a complex interweaving of dynamic forces. In each of our essays, we attempt to unpack these dynamic forces in three very different sets of texts and practices. Moruzi's essay focuses on British and Canadian girls' periodicals and novels, while Alexander looks at the Girl Guide movement. My work is essentially about the relationship children have to the media marketplace. I am particularly interested in how the media and market research build their sense of children as consumers. My scholarship is based in the discipline of communication studies, which is itself partly grounded in political economy. The purpose of political economy is to understand the complex, synergistic processes that take place between the various sectors of the marketplace as each sector works to produce economic value. In my work, these two theoretical perspectives intersect in an analysis of the market segmentation of young people into categories that meet the logic and needs of the marketplace in late capitalism.

As a parent of young children, I am continually reminded of the corporate power of the Walt Disney Company as it seeps into virtually all facets of my children's lives: from the birthday parties they attend to the clothes they wear to the books they read at night, Disney is there. Children can immerse themselves in the Disney brand and move through it as they age, 
never leaving the warm, cuddly embrace of the Disney Company. This immersion can begin even before children are born, when expectant parents can furnish their baby's entire nursery with Disney Baby products. These parents face many possibilities. Do they choose the delicate and sweet Minnie Mouse line of products or the whimsical line of Winnie-the-Pooh? Once the baby has been brought home, Disney's Baby Einstein media products can entertain the little bundle of joy for hours.

As children grow into toddlers and need more stimulation than Baby Einstein, they can graduate to Disney's multi-platform preschool brand, Disney Junior, which is also a global television channel. Then, as children become school-aged and start to segregate into gendered categories, girls can migrate to the Disney Princess line of toys, clothes, movies, and books, while boys can move on to the Disney XD channel, play on the Disney XD website, and buy the whole accompanying line of products.

Once these products become too juvenile for children, Disney offers a whole slew of "soft" teen media franchises such as Camp Rock, High School Musical, and Hannah Montana, as well as newer media franchises such as Austin \& Ally, A. N. T. Farm, and Shake It Up. These franchises all work on the same formula of showcasing the zany hijinks of musical teens as they navigate the trials and tribulations of high school clique culture. They omit anything too edgy or close to the realities of teen life, offering instead a nice, bubble-gum version of adolescence.

Finally, when children become teenagers and start to think they are too old for Disney, there are franchises like Pirates of the Caribbean to prevent them from ever needing to leave the corporate cocoon of Disney. Beginning as a ride at the amusement park, this franchise has since spawned a full transmedia platform that began with a cycle of films but also includes online games, books, soundtracks, and even board games. When these teens eventually become adults and have their own children, the cycle can start all over again.

As a scholar of critical advertising studies, what I find so frightening about the corporate power of Disney is the extent to which it contributes to the framing of these narrow segments of young people. Disney could be the poster child for compartmentalizing young people into discrete marketing niches. Taking stock of Disney's massive media holdings reveals clearly that Disney is keenly aware of the market segmentations of young people along lines of age and gender (Walt Disney Company, "Company"). Disney knows who these markets are, what they want, where to find them, and how to talk to them.

Disney is not the only global conglomerate in the children's media marketplace to follow such a business strategy, but what this example reveals is how young people have become fractured across age 


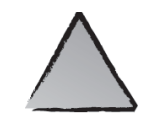

... in the past one hundred years, the children's media marketplace has become one of the key institutions to frame categories of young people discursively.

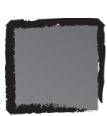

and gender lines into narrower segments that offer more intense marketing opportunities for global conglomerates. Young people are understood according to the needs of the corporate (and adult) imaginary. The Disney example opens up opportunities to explore how the commercial categories of youth, such as the toddler, the tween, and the teen, are structured and organized to meet adultorientated needs of neo-liberal capitalism.

My work builds on the theoretical framings of critical childhood studies that suggest that the categories of young people are socially, culturally, politically, and economically constituted within particular moments and spaces (see Jenkins; James; Zezlier). These constitutions serve the needs of adult-centred social, cultural, political, and economic systems. In my own scholarship on the development of the tween girl in the 1980s, it has become clear to me that in the past one hundred years, the children's media marketplace has become one of the key institutions to frame categories of young people discursively.

I want to begin the exploration of the market segmentation of youth with a word I found in the trade press in an article in Advertising Age from the early 1990s: "discover." The advertising industry had declared that it had "discovered" the tween girl (Waldrop). This was not the first time I had read this word in relation to the children's market. In an interview in 1951 in Advertising Age, teen marketing guru Eugene Gilbert declared that the "salient discovery is that ... teens have become a separate and distinct group in society" (qtd. in Palladino 109). Meanwhile, almost forty years later in 1988, Peter Franchese, the editor of American Demographics, a magazine read closely by the advertising industry, stated that "the trick is to find a faster-growing segment 
before everyone else does" (qtd. in Turow 55). While Franchese in this quotation does not use the word discover, the implication is similar. In my work I am intrigued and troubled by the concept of "discovering" or "finding." On the one hand, I find myself laughing at the arrogance of the marketing industry, the pretense that marketers are the great explorers of global capitalism, boldly braving the wilds of youth culture armed with only their wits, their skills, and a backpack full of market research tools, and laying claim to new lands and peoples. On the other hand, however, the word provides disturbing insights into the ways that the dynamic forces of capitalism work to segment young people into narrow market niches that offer more intense marketing opportunities for companies.

The term opens up questions that drive my research, some of which I have answered and some of which I am only starting to answer, particularly in the context of tween girls. Who was "discovered," and who exactly were the "discoverers"? What were young people doing to warrant their discovery? How were they "discovered"? What does it mean to be "discovered"? Where were they before their discovery? Finally, what do those who are supposedly discovered "do" with their new-found discovery? I am not the first person to question this term. In 1992, business scholars Stanley C. Hollander and Richard Germain asked a similar question in the title of their book Was There a Pepsi Generation Before Pepsi Discovered It? While their work traced the development of youth segmentation as a historical event, it failed to ask the critical questions that are implied in the term "discovery."

The word "discover" alludes to colonization, of finding a people and a place for the purposes of appropriation (see the Oxford English Dictionary). Under the system of colonization, new colonies are valuable as they offer the imperial powers access to new material resources for exploitation and new opportunities for markets to sell their goods. In the past century, young people have become similarly valuable. They provide opportunities for new resources of subjectivity and for new markets. Judith Williamson writes in her seminal article "Woman Is an Island: Femininity and Colonization" that capitalism is "constantly searching for new areas to colonize" (116). The value of young people to capitalism has been noted by many, including Stuart Ewen, who observed in his 1976 work Captains of Consciousness that turning young people into consumer markets has been essential for the continuation of capitalism. As Daniel Cook has so eloquently stated, "childhood makes capitalism hum over the long haul" ("Lunchbox Hegemony").

The colonization of new markets provides an outlet for overproduction. As William Leiss and his colleagues suggest, the productive capacity of capitalism is always growing, always searching for new ways to produce more goods (and services) more cheaply and efficiently. 
As it does this it has to search constantly for new markets to purchase these goods (20). Young people have provided a perfect segment of the population to colonize as new markets. Companies have fractured the life course of young people along age and gender lines in the production/colonization of narrower and tighter market segments. Ultimately, the claim of "discovering" by marketers is really the proclamation of the beginning of the discursive production of youth markets into smaller segments (or colonies, to continue with the metaphor I have been using).

In the early twentieth century, young consumers were grouped into two rudimentary units: the child and the adolescent. These were vague, cumbersome, and crudely defined categories. Throughout the twentieth century, childhood became segmented into smaller and tighter marketing niches that offered more intense marketing moments. For example, Cook has explored how in the 1930s the children's apparel industry worked with the retail industry to demarcate the toddler as a specific stage of childhood that warranted its own distinctive merchandising categories. Both Kelly Schrum and Ilana Nash have argued that the teenage girl became a nuanced market in the 1940s and 1950s as high school girls began to demand attention from the magazine, fashion, beauty, and music industries. In response, these industries worked to define and explain the teenage girl to baffled adults. In my own work on the development of the tween girl in the 1980s and early 1990s, I suggest that the tween became a separate and distinct marketing niche as the advertising, marketing, and media industries began to notice the value in addressing the preteen girl as separate from the teenager or the child (Coulter, "Consumption"; Coulter, "Selling"). And now marketers talk of the pretween market (see, for instance,

Cytrynbaum; O’Donnell).

At various moments in the last century, the children's media marketplace discovered these various new markets and colonized them as consumers. ${ }^{1}$ Postcolonial scholar Homi Bhabha informs us that colonial power is exercised through the articulations of difference of the colonial subject (390). Bhabha argues that colonization is about using difference as a means to "justify conquest and establish systems of administration" where the colonized is discursively produced as the "other" (391). In applying Bhabha's reading of colonialism to the colonization of young people as markets, I argue that young people are discursively situated as "other." They are othered from adults and labelled with terms such as tween, toddler, and teen. This fits the needs of the media marketplace quite well: because children are viewed as something "other" than adults, they are believed to require a separate set of commodities that can only be provided by those who intimately know this "other." These providers are companies like Disney who, as we are reminded in its promotional materials, understand 
childhood as a "special" and "magical" space that is unlike adulthood (Walt Disney Company, "Company").

As companies like Disney began to colonize young people as the other, the toddler, the teen girl, the tween, and even the pretween became known as specific segments and became visible within the children's media marketplace. ${ }^{2}$ Knowing and making visible are evocative of the processes of colonial discourse that, as Bhabha argues, "produces the colonized as a social reality which is at once an 'other' and yet entirely knowable and visible" (391). This discourse is a system that Bhabha calls a "regime of truth," in which the colonizer controls the colonized through finding out everything about the colonized and using this knowledge to construct an identity of the colonized in a unified and coherent way. In applying the logic of Bhabha's argument to the segmentation of childhood, I argue that children become "known," are "made visible," and are produced as "unified" (to use Bhabha's terms) at three specific moments in the discursive processes of the production of consumption.

The first moment, I suggest, is in knowing who precisely is in the market segment. Essentially, markets are socially constructed categories of meaning. They are a way of making sense of specific populations for the purposes of selling products and maximizing profits. Market segmentation is a means of apprehending human activity (Cook, "Other" 487), and it is a form of social organization in which the consumer becomes the object of the "market research gaze" (Cook, Commodification 19). Companies like Disney dedicate vast amounts of resources to "know" the audience/consumer. Recently, for example, Disney hired child psychologists, anthropologists, educators, and even self-described "kid whisperer" Kelly Pena, in order to understand and "know" the boy market (Giroux and Pollock).

The second moment, I argue, is in knowing the consumer as a customer, which means knowing what to produce for the various youth markets. Marx tells us that production only has value if there is a market for a particular good, what Marx terms a "use value." Knowing the lifestyles and values of a market means that merchandisers, product designers, and retailers are able to provide commodities that meet the potential needs, wants, and desires of a group of consumers. Obviously, there are lots of opportunities for failure here. Dollar store remainder bins are full of goods for which merchandisers and retailers mistakenly thought there was a market that had a use value for the items.

The third moment is in locating consumers as an audience in order to inform them of the new products available to them. The political economist Dallas Smythe tells us that the media exist to sell audiences to advertisers. He suggests that the audience is a commodity that is sold to advertisers. The media produce programs that gather specific audiences who are seen as valuable markets by advertisers. In 
addition to producing content, part of the job of a media company such as Disney is to be able to convey the potential value of its audiences to advertisers, and, in doing so, Disney makes the audience visible. It is in the best interests of companies to fracture young people in smaller, more targeted niche audiences that can be "known" more intimately because they provide more intense marketing opportunities.

Together these three stages of the discursive production of child consumers are similar to what Bhabha has called the "regime of truth" employed by colonizers. Each moment provides more intense commercial opportunities as categories of young people such as the toddler, the teen. and the tween are rendered "knowable," made "visible," and produced as "unified" by the vast discursive frames of market research available to companies such as Disney in their quest to colonize young people as new markets.

Discourses, as Foucault reminds us in Archaeology of Knowledge, are productive processes that define and produce objects of knowledge. Market research is a "performative science" as it is a body of expertise that simultaneously describes and constructs its subject matter (Cochoy 198). In being produced discursively as audiences, markets, and customers, young people are known and made visible according to the logic and needs of the marketplace. What is concerning is how within these processes young people are produced discursively in purely commercial terms and are reduced to objects so that they can be "commodified and marketed back to themselves, stripped of any history, individual identity or power," according to Henry Giroux (qtd. in Brooks 13). Many young people continue to be colonized literally, such as Aboriginal youth in Canada, who are largely ignored and rendered invisible by a media marketplace that is interested only in colonizing categories of young people who can add value to the media marketplace as consumers.

In the colonization of youth markets, age and gender have become the signifiers of difference that are used in the processes of subjugation. While there is a long history of the youth market being fractured along the lines of age and gender, this became particularly intense in the 1980s under the hegemony of neo-liberal ideologies that privileged market values over individual needs. There were two specific events that occurred during the 1980s that were critical to the escalation of the colonization of youth markets based on gender and age.

The first event was the dramatic advancement of technology in the television industry that allowed for the development of cable television. With cable television and its plethora of television channels, the new focus in the media marketplace shifted from broadcasting to an emphasis on narrowcasting with its small, tailored audiences. In the 1980s, cable stations such as MTV and Nickelodeon launched in the United States, while in Canada MuchMusic, YTV, and the 


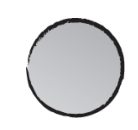

With the deregulation of the separation between the programs and the commercials, television programs became de facto commercials for a broad range of toys and merchandise.

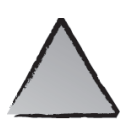

Family Channel all began to fracture audiences along the lines of age (Coulter, "Selling"). Stratifications in age became critical in the "regime of truth" that articulated and organized difference according to the needs and logic of colonial power and of the children's media marketplace.

The second shift that occurred was a move to deregulate children's media as the Federal Communication Commission (FCC) and the Federal Trade Commission (FTC) in the United States swayed under the pressures of neo-liberalism and off-loaded many of their responsibilities to regulate children's media onto the industry itself in the form of self-regulation. The lifting of a number of regulations, including removing the restrictions on the separation between programs and commercials and increasing the allowable number of commercial minutes per hour, meant that children were no longer protected from the commercial forces of the marketplace. These changes also legitimated children as consumers and meant that gender would become more entrenched as part of the discursive processes of producing the colonized.

With the deregulation of the separation between the programs and the commercials, television programs became de facto commercials for a broad range of toys and merchandise. Shows featuring Strawberry Shortcake became thirty-minute promotional vehicles for Strawberry Shortcake dolls, books, toys, clothes, and whatever else could be licensed. The impact of this was that it became worthwhile for children's media producers to segment the audience by gender, given that the value of the children's audience was no longer based on how many child viewers could be delivered to advertisers, but rather on the purchasing power of a smaller market (see Seiter; Coulter, "Selling"). 
The implication of these two shifts in the neo-liberal spaces of the 1980s was that there was even more of an impetus to fracture young people into smaller, tighter markets based on age and gender. In the 1980s, age and gender became further legitimated and entrenched as the key subjective boundaries in the categorization of youth. These are now the hegemonic markers in knowing the youth market and the visible signifiers of difference from the adult as young people are produced as coherent and unified categories within age and gender boundaries.

Of course, like the process of colonization, the segmentation of young people has taken place within a rigid set of dominant discourses that have failed to address a wide range of demographics and subjectivities. Age and gender are privileged while other subjectivities such as class, race, ethnicity, and sexuality are rendered invisible. Young people are conflated into a singular identity, in a process similar to that described by Edward Said, in which imperial discourses constitute the colonized "as a unified racial, geographical, political and cultural zone of the world" (qtd. in Bhabha 391). In this way, these categories of youth (toddlers, tweens, and teens) are not local, regional, or national, but global assemblages coordinated by the forces of neo-liberal capitalism as part of a production of a global youth culture in which young people's territories, as Macgregor Wise has stated, have "non-local connections" (56).
To take Disney's production of the categories of childhood as an example, the preschooler, the tween, and the teen cross global territories and boundaries. Disney Junior is available in twenty-nine languages and in 156 countries or territories with a global reach of over 45 million households. The Disney Princess Books are sold in more than ninety countries. In Disney's 2010 annual report, the company boasted that in that year they launched twenty new Disney XD stations in the Middle East and Africa. Disney has fractured the youth market along age and gender lines, but the narrow segments such as the toddler, the tween, and the teen are produced as homogenous global assemblages. The tween boy in Uganda can watch virtually the same media content as his Canadian counterpart. Disney focuses on the unity of this aged and gendered cohort as opposed to any differences. This is not to imply that young people are homogenous and uniform but that young people are discursively produced by transnational corporations as coherent and uniform. This coherence is then mobilized by these corporations across global spaces as the "knowing" or "colonization" of the categories of young people become global assemblages.

The value in this is that uniformity is cheap for conglomerates like Disney. Uniformity requires little change in the media content. It is part of the global impetus of neo-liberal capitalism to discover, produce, and reproduce homogenous categories of young people across and beyond national borders in ways that 
emphasize young people as consumers only and not as political beings. This homogeneity is not static, however. It is constantly being reworked and reconfigured within the flows of the global marketplace. Unfortunately, however, as Norma Pecora and Katalin Lustyik point out in their recent article in Journal of Children and Media, there is little scholarly research on media globalization and children.

Wider questions about what the fracturing of youth into smaller categories offers the entire system of capitalism beyond the opportunity to exploit new markets need to be asked. Wise suggests that the term teenager in places like Nepal is used to teach the elite the language of consumerism (56). The term "teenage" is not as much an age category but "a desired condition, a way of life that can be achieved through a range of consumer behaviours," according to Mark Liechty (qtd. in Wise 55). There is a lot of value in this type of argument. The globalization of youth culture provides opportunities to preach the values of consumption as a source of pleasure and subjectivity.

There is also something more: I would argue that segmenting youth into tighter categories that are based around age and gender while ignoring other categories of subjectivity as critical aspects of identity functions as a way to naturalize the consumptive practices of neo-liberal capitalism as a component of human subjectivity. If we historicize youth within the context of Piaget and Erickson's conceptualization of human development as a series of physiological and social stages of development through which humans naturally progress as they age and develop, then defining the physiological and developmental stages of youth according to the logic of the marketplace works as a way to reify participation in consumer culture as a basic human need. The child offers more than just a market; selling to the child cements ideological values around consumption as it reifies the consumptive practices of neo-liberal capitalism as part of the natural state of development of the postmodern subject.

Since the 1980s, the commercialization and segmentation of the youth market has intensified. New market segments such as the tween and now the pretween have become stable marketing categories that entrench age and gender further as the central subjective boundaries of youth in the media marketplace. Each of these new markets is discursively articulated in the synergistic relations of the children's media marketplace as market researchers work to get to know them as markets, as advertisers, retailers, and merchandisers try to cull young people as customers, and as media companies attempt to define them as audiences. While there is still much work to be done in terms of how these processes work, particularly in the context of neo-liberal capitalism, there are many other necessary questions that have not yet been asked. As scholars of critical childhood studies, we need to explore the tensions between the discursive productions 
of childhood and the lived experiences of embodied young people. We need to ask what these segmentations offer children. Clearly, young people have to buy into this segmentation in order for it to be financially viable, so what does it offer them? What do children do with these discursive productions of market segments? How do they engage with them? Disney did not become the huge global corporation it is without children participating in its categorizations of childhood at some level. Until we ask these questions, we will not be able to appreciate fully what it means for young people to have been "discovered."

\section{Notes}

1 Of course, it is important not to minimize the fact that the processes of colonization have often been racist and violent forms of oppression. I am using the term colonization metaphorically as it allows insight into the processes of market segmentation and the processes of the commodification in which young people are framed as subjects in ways that meet needs of the colonial power, in this case the imperial powers of the marketplace.

${ }^{2}$ These categories are made visible in multiple ways. This includes being referred to in trade journals, having market researchers write reports on the category, and having a media company describe and explain the category as an audience.

\section{Works Cited}

Bhabha, Homi. "The Other Question: Stereotype, Discrimination and the Discourse of Colonialism." The New Social Theory Reader: Contemporary Debates. Ed. Steven Seidman and Jeffrey C. Alexander. New York: Routledge, 2001. 388-402. Print.

Brooks, Karen. “Nothing Sells Like Teen Spirit: The Commodification of Youth Culture." Youth Cultures: Texts, Images and Identities. Ed. Kerry Mallan and Sharyn Pearce. Westport: Praeger, 2003. 1-16. Print.

Cochoy, Frank. "Another Discipline for Market Economy: Marketing as Performative Knowledge and Know-How for Capitalism." The
Laws of the Markets. Ed. Michel Callon. Oxford: Blackwell, 1998. 194-221. Print.

Cook, Daniel. The Commodification of Childhood: The Children's Clothing Industry and the Rise of the Child Consumer. Durham: Duke UP, 2004. Print.

---. "Lunchbox Hegemony." Consumers, Commodities \& Consumption 5.2 (2004). Web. 5 June 2012.

---. "The Other 'Child Study': Figuring Children as Consumers in Market Research, 1910s-1990s." Sociological Quarterly 41.3 (2000): 487-507. Print. 
Coulter, Natalie. "The Consumption Chronicles: Tales from Suburban Tweens." Seven Going on Seventeen. Ed. Claudia Mitchell and Jacqueline Reid-Walsh. New York: Lang, 2005. 330-45. Print.

---. "Selling Youth: Youth, Media and the Marketplace." Mediascapes. 3rd ed. Ed. Paul Attallah and Leslie Regan Shade. Toronto: Nelson, 2009. 149-64. Print.

Cytrynbaum, Pamela. "Pre-Tween Silent Scream: Watching Your Daughter's Self-Esteem Plummet." Psychology Today 2 Oct. 2009. Web. 9 June 2012.

Ewen, Stuart. Captains of Consciousness: Advertising and the Social Roots of the Consumer Culture. New York: McGraw-Hill, 1976. Print.

Foucault, Michel. Archaeology of Knowledge. New York: Pantheon, 1972. Print.

Giroux, Henry, and Grace Pollock. "How Disney Magic and the Corporate Media Shape Youth Identity in the Digital Age." Truth Out 21 Aug. 2011. Web. 16 Feb. 2012.

Hollander, Stanley C., and Richard Germain. Was There a Pepsi Generation Before Pepsi Discovered It?: Youth Based Segmentation in Marketing. Lincolnwood: NTC, 1992. Print.

James, Allison, Chris Jenks, and Alan Prout. Theorizing Childhood. Cambridge: Polity, 2004. Print.

Jenkins, Henry. "Childhood Innocence and Other Myths." The Children's Culture Reader. Ed. Henry Jenkins. New York: New York UP, 1998. 1-35. Print.

Leiss, William, et al. Social Communication in Advertising. 2nd ed. New York: Routledge, 2005. Print.

Marx, Karl. Capital. New York: Basic, 1976. Print.

Nash, Ilana. American Sweethearts: Teenage Girls in Twentieth Century Popular Culture. Bloomington: Indiana UP, 2006. Print.
O'Donnell, Jane. "As Kids Get Savvy, Marketers Move Down the Age Scale." USA Today 13 Apr. 2007. Web. 9 June 2012.

Palladino, Grace. Teenagers: An American History. New York: Basic, 1996. Print.

Pecora, Norma, and Katalin Lustyik. "Media Regulation and the International Expansion of Nickelodeon." Journal of Children and Media 5.1 (2011): 4-19. Print.

Schrum, Kelly. Some Wore Bobby Sox: The Emergence of Teenage Girls' Culture 1920-1945. New York: Palgrave, 2004. Print.

Seiter, Ellen. Sold Separately: Children and Parents in Consumer Culture. New Brunswick: Rutgers UP, 1993. Print.

Smythe, Dallas W. "Communications: Blindspot of Western Marxism." Counterclockwise: Perspectives on Communication. Ed. Thomas Guback. Boulder: Westview, 1994. 263-91. Print.

Turow, Joesph. Breaking Up America: Advertisers and the New Media World. Chicago: U of Chicago P, 1997. Print.

Waldrop, Judith. "The Tween Scene." American Demographics Sept. 1992: 4. Print.

Walt Disney Company. "Annual Report 2010." The Walt Disney Company, n.d. Web. 16 Feb. 2012.

Walt Disney Company. "Company Overview." The Walt Disney Company, n.d. Web. 16 Feb. 2012.

Williamson, Judith. "Woman Is an Island: Femininity and Colonization." Studies in Entertainment: Critical Approaches to Mass Culture. Ed. Tania Modleski. Bloomington: Indiana UP, 1986. 99-118. Print.

Wise, Macgregor. Cultural Globalization: A User's Guide. Carlton: Blackwell, 2008. Print.

Zezlier, Viviana. Pricing the Priceless Child: The Changing Social Value of Children. Princeton: Princeton UP, 1985. Print. 
Natalie Coulter teaches in the Department of Communication Studies at York University. She is currently working on her book entitled Tweening the Girl: The Crystallization of the Tween Market, 1980-1996. She is interested in the relationships between the advertising and marketing industries and socio-cultural constructions of childhood. She is also working on various projects that explore the history of children's cultural industries in Canada. She was a founding member of the Association for Research in Cultures of Young People. 